\title{
Şebekeden Bağımsız Eviriciler için Sinüzoidal Darbe Genişlik ve Uzay Vektör Darbe Genişlik Modülasyonlarının Karşılaştırılmalı Performans Analizi
}

\author{
İbrahim Arslanoğlu ${ }^{1 *}$, Bilgin Zengin ${ }^{2}$ \\ ${ }^{1}$ Karadeniz Teknik Üniversitesi, Mühendislik Fakültesi, Elektrik Elektronik Mühendisliği, Trabzon, Türkiye \\ ${ }^{2}$ Munzur Üniversitesi, Mühendislik Fakültesi, Elektrik Elektronik Mühendisliği, Tunceli, Türkiye \\ *ibrahimarslanoglu@ktu.edu.tr (iD, bilginzengin@munzur.edu.tr iD \\ Makale gönderme tarihi:03.06.2021, Makale kabul tarihi: 29.09.2021
}

\begin{abstract}
$\ddot{O} z$
Birçok sistemde yaygın olarak alternatif akım kullanıldığından doğru akım giriş geriliminin istenilen genlik ve frekansta simetrik bir alternatif akım çıkış gerilimine dönüştürülmesi istenmektedir. Bu amaçla, çalışmada öncelikle eviriciler ve çok seviyeli eviriciler hakkında bilgi verilmiştir. Daha sonra, darbe genişlik modülasyon teknikleri açılanmış ve bu modülasyon teknikleri içerisinden Sinüzoidal Darbe Genişlik Modülasyon (SDGM) ve Uzay Vektör Darbe Genişlik Modülasyon (UVDGM) tekniklerinin çalışma mantı̆̆ı detaylıca incelenmiştir. Son olarak, MATLAB/Simulink ortamında şebekeden bağımsız iki seviyeli SDGM ile üç seviyeli UVDGM kontrol yöntemi kullanılarak eviricilerin, R (Rezistif) ve R-L (Rezistif-Endüktif) yükleri üzerindeki benzetimleri modellenmiştir. Simulink ortamında yapılan bu ölçümler, teorik hesaplamalarla kıyaslanmış ve modellerden güç kalitesi açısından en iyi performans gösterenin hangisi olduğu belirlenmeye çalışlmıştır.
\end{abstract}

Anahtar Kelimeler: Çok seviyeli eviriciler, eviriciler, sinüzoidal darbe genişlik modülasyonu, uzay vektör darbe genişlik modülasyonu

\section{Comparative Performance Analysis of Sinusoidal Pulse Width and Space Vector Pulse Width Modulations for Off-Grid Inverters}

\begin{abstract}
Since alternating current is widely used in many systems, it is desired to convert the direct current input voltage to a symmetrical alternating current output voltage with the desired amplitude and frequency. For this purpose, first of all, information about inverters and multilevel inverters is given in the study. Then, pulse width modulation techniques are explained and the working logic of Sinusoidal Pulse Width Modulation (SPWM) and Space Vector Pulse Width Modulation (SVPWM) techniques are examined in detail among these modulation techniques. Finally, the simulations of the inverters on R (Resistive) and R-L (Resistive-Inductive) loads are modeled using the grid-independent two-level SPWM and three-level SVPWM control method in MATLAB/Simulink environment. These measurements made in the Simulink environment were compared with the theoretical calculations and it was tried to determine which of the models showed the best performance in terms of power quality.
\end{abstract}

Keywords: Multi-level inverters, inverters, sinusoidal pulse width modulation, space vector pulse width modulation

\section{GİRIȘ}

Günümüzde birçok sistemde ve endüstriyel uygulamalarda genel olarak alternatif akım (AA) kullanılmaktadır. Bu yüzden doğru akım (DA) giriş gerilimin AA çıkış gerilimine dönüşümünün yapılması gerekmektedir. Bu dönüşüm yapılırken giriş gerilimi istenilen genlikte ve frekansta simetrik bir AA çıkış gerilimine dönüştürülmesi istenmektedir. Dolayısıyla, DA'nı AA dönüşümünde meydana gelecek kayıpların en az olması hem enerji kaybını önleme açısından hem de sistem performansı açısından önem arz etmedir.

Eviriciler, DA'yı AA'ya dönüştürürken çıkışta düşük harmonik elde etmeyi sağlayan güç elektroniği devresidir. $\mathrm{Bu}$ yüzden endüstriyel uygulamanın vazgeçilmezleri arasındadır. Çünkü çeşitli motorların denetimi, güç sistemleri gibi geniş bir kullanım alanına sahiptir. Bu yaygın kullanım alanına sahip olan eviricilerden beklenen en temel özellik DA giriş geriliminin istenilen genlikte ve frekansta AA çıkış 
gerilimine dönüştürülmesidir. Diğer bir deyişle; çıkış gerilim dalga şeklinin olabildiğince sinüs formuna yaklaşmış olması beklenmektedir. (Beşer, 2009).

\section{MATERYAL VE METOT \\ Eviriciler}

Eviriciler, DA giriş kaynağ 1 enerjisini istenilen genlik ve frekansta yüke uygulanan AA çıkış enerjisine dönüştüren güç elektroniği devreleridir (Önder, 2010). Bu dönüştürülen evirici çıkış enerjisinin ve geriliminin istenilen seviyede ayarlanması çeşitli yöntemlerle sağlanmaktadır. Birinci yöntem; evirici kazancını sabit tutarak DA giriș gerilimini ayarlamakla yapılır. İkinci yöntem ise DA giriş geriliminin sabit ve kontrol edilemediği durumlarda, eviriciye genellikle darbe genişlik modülasyonu (DGM) uygulanarak değişken çıkış gerilim seviyesinin elde edilmesi ile yapılır (Yumurtac1, 2007).

\section{Çok Seviyeli Eviriciler}

Yarı iletken teknolojisinde kaydedilen gelişmelerle beraber farklı DGM tekniklerinin de geliştirilmesi güç dönüştürücülerinin ortaya çıkmasına ve birçok alanda kullanılmasına olanak sağlamıştır. Bu gelişmelerden biri de çok seviyeli eviricilerdir. Özellikle kesintisiz güç kaynakları ve sürücü sitemleri gibi endüstriyel uygulamaların birçoğunda yaygın olarak kullanılan bu eviriciler, girişlerine uygulanan DA gerilim seviyelerini çıkıșlarında daha sinüzoidal forma dönüștürürler (Sünter, 2013).

Çok seviyeli eviricinin en büyük faydası, anahtarlama frekansını arttırmadan ya da evirici çıkış gerilimini azaltmadan evirici çıkışındaki dalga formunda meydana gelen harmonik bozulmaları minimize etmesidir (Kocatepe ve diğerleri, 2003).

Çok seviyeli eviricilerin çıkışındaki dalga şekli sinüs sinyalinin merdiven basamaklı hali gibidir. Girişine uygulanan gerilim seviye sayısı arttıkça çıkışındaki dalgada oluşan basamak sayısı da artacağı için dalga formu sinüs sinyal şekline daha çok benzeyecek ve kalitesi de artacaktır. Fakat seviye sayısını arttırdıkça anahtarlama eleman sayısı da artacağı için evirici kontrol algoritmasındaki karmaşa da artacaktır. $\mathrm{Bu}$ da çok seviyeli eviricilerin istenmeyen durumudur (Kerem, 2012).

Orta ve yüksek güç uygulamalarında kullanılan klasik eviricilerin verimlerinin düşük olması, büyük transformatörlerin kullanılmasıyla ortaya çıkan yüksek maliyet, $\mathrm{dV} / \mathrm{dt}$ ve $\mathrm{dI} / \mathrm{dt}$ sonucu anahtarlama elemanlarında oluşan akım-gerilim darbeleri gibi istenmeyen durumlar, çok seviyeli eviricilerin geliştirilmesiyle en aza indirilmeye çalışılmıştır. Böylece yüksek güç uygulamaları için yeni bir güç dönüşüm sistemi ortaya çıkmıştır.

Çok seviyeli eviricilerde gerilim seviyesi en az üç ile başlar ve sonsuz seviyeye kadar gidebilir. Arttırılan her seviye sonucunda çıkış gerilim dalga formunda; daha az sinyal bozulumu, daha düşük anahtarlama frekansı ve yüksek verim gibi durumlar meydana gelir.

Çok seviyeli eviriciler üretim zamanlarına ve türlerine göre: Diyot Kenetlemeli Çok Seviyeli Evirici, Kapasite Kenetlemeli Çok Seviyeli Evirici, İzoleli DA Kaynaklı Kaskat Bağlı Çok Seviyeli Evirici şeklinde üç grupta sinıflandırılabilir (Kocalmış Bilhan, 2012).

\section{Darbe Genişlik Modülasyon Teknikleri}

Evirici çıkışındaki gerilim ve frekansın kontrolüne ilişkin birçok çalışma yapılmış ve bu çalışmalar neticesinde birçok teknik geliştirilmiştir. $\mathrm{Bu}$ tekniklerle evirici çıkışındaki dalganın sinüzoidal şekle yaklaşması amaçlanmıştır. Böylece harmonik bozulma azaltılarak çıkış dalga kalitesi arttırılmıştır. $\mathrm{Bu}$ teknikler genel olarak DGM olarak ifade edilmesine rağmen geniş bir lineer modülasyon aralığı, daha az anahtarlama kaybı, kolay uygulama ve daha az toplam harmonik bozulum elde etmek amacıyla birçok farklı adla anılan DGM tekniği mevcuttur. Her tekniğin kendince çeşitli avantaj1, dezavantaj1 ve her birinin farklı türde uygulama alanları vardır. $\mathrm{Bu}$ teknikler şunlardır: Sinüzoidal Darbe Genişlik Modülasyonu (SDGM), Uzay Vektör Darbe Genişlik Modülasyonu (UVDGM), Harmonik Eliminasyonlu Darbe Genişlik Modülasyonu (HEDGM), Minimum Akım Dalgalanmalı Darbe Genişlik Modülasyonu (MADDGM), Üçüncü Harmonik İlaveli Darbe Genişlik Modülasyonu (UHIDGM), Harmonik İlaveli Darbe Genişlik Modülasyonu (HIDGM), Değiştirilmiş Sinüzoidal Darbe Genişlik Modülasyonu (DSDGM), Sigma Delta Darbe Genişlik Modülasyonu (SDDGM).

\section{Sinüzoidal Darbe Genişlik Modülasyonu}

$\mathrm{Bu}$ teknik endüstriyel uygulamalarda en çok tercih edilen tekniklerden biridir. İki seviyeli SDGM tekniğinin geliştirilmesiyle çok seviyeli eviricilerde kullanılmaktadır. Yüksek frekanslı tepe genliği $V_{\text {üçgen, frekansı }} f_{t}$ olan taşıyıcı üçgen dalga ile daha düşük frekanslı tepe genliği $V_{p}$ ve frekansı $f_{r}$ olan bir 
sinüs işareti karşılaştırılarak tetikleme sinyallerinin üretimine dayalı olan yönteme SDGM denir3. (Fidanboy, 2011).

SDGM tekniği kare dalgadaki harmonikleri azaltmak için kullanılan en eski yöntemlerden biridir (Kang ve diğerleri, 2000). Ayrıca sinüs biçimde bir gerilim elde etmek için kullanılan en ekonomik ve en4. kolay uygulanabilen yaygın yöntemlerdendir (Asker ve diğerleri, 2009).

SDGM tekniğinde, modülasyon dalga genliğinin5. taşıyıcı dalga genliğine oranına modülasyon indeksi denir. $\mathrm{Bu}$ oranın lineer olabilmesi için modülasyon indeksinin 0 ile 1 arasında değişen bir değerde olması gerekmektedir. Modülasyon indeksi ve frekans indeksi şu şekilde hesaplanır (Tuncer, 2004);

$$
\begin{gathered}
M_{i}=\frac{V_{t}}{V_{\text {issgen }}} \\
M_{f}=\frac{f_{t}}{f_{r}}
\end{gathered}
$$

Yukarıdaki formüllerde;

$\mathrm{M}_{\mathrm{i}}$ modülasyon indeksini, $\mathrm{V}_{\mathrm{p}}$ taşıyıcı işaretin genliği, $\mathrm{M}_{\mathrm{f}}$ frekans indeksini, $\mathrm{f}_{\mathrm{t}}$ taşıyıcı işaretin frekansını ve $\mathrm{f}_{\mathrm{r}}$ referans işaretin frekansı göstermektedir.

Modülasyon indeksine ait dört durum söz konusudur. Bunlar:

1. 1. $\mathrm{M}_{\mathrm{i}}=0$ olduğunda çıkışta anahtarlama frekansında kare dalga meydana gelir.

2.

2. $0 \leq \mathrm{M}_{\mathrm{i}} \leq 1$ ise temel bileşen tepe değeri $\left(\mathrm{V}_{0}\right)$ ile $\mathrm{M}_{\mathrm{i}}$ lineer değişmektedir.

$$
V_{0}=M_{i} \cdot \frac{V_{D A}}{2}
$$

hale getirmektir. Bu yüzden eviricideki anahtarların olası tüm durumları birer anahtarlama vektörüyle ifade edilir. $\mathrm{Bu}$ vektörlere ait anahtarlamaların tüm kombinasyonları matematiksel ifadeler yardımıyla belirlenerek en uygun anahtarlama durumu seçilir.

Üç seviyeli eviricide çıkış geriliminin elde edilmesi için şu adımlar takip edilir;

1.Adım: $\mathrm{V}_{\mathrm{d}}, \mathrm{V}_{\mathrm{q}}, \mathrm{V}_{\text {ref }}$ gerilimleri ve $\theta$ açısı hesaplanır. 2.Adım: $V_{\text {ref }}$ 'in hangi sektörde olduğu belirlenir. 3.Adım: $V_{\text {ref }}$ 'in sektörün hangi bölgesinde olduğu belirlenir.
3. $\mathrm{M}_{\mathrm{i}}=1$ ise temel bileşen $0.5 \mathrm{~V}$ değeri alır. Lineer bölge için maksimum değer olan bu değer, eviricinin oluşturabileceği maksimum değer olan $\left(4 \mathrm{~V}_{\mathrm{DA}} / 2 \pi\right)$ kare dalga durumunun $\% 78.55$ 'ine tekabül eder.

4. $\mathrm{M}_{\mathrm{i}}>1$ ise aşırı modülasyon bölgesidir. $\mathrm{Bu}$ bölgede lineerlik bozulur. $\mathrm{M}_{\mathrm{i}}$ belli bir değerinden sonra kare dalga oluşur (Fidanboy, 2011).

Eviricilerde çıkış gerilimiyle kontrol sağlandığı gibi çıkış frekansıyla da kontrol sağlanabilir. $\mathrm{Bu}$ kontrol Denklem (2)'de verilen formülle hesaplanır. Yüksek frekanslı harmoniklerin daha kolay filtrelenebildiği göz önünde bulundurulunca, anahtarlama frekansının da o oranda yüksek olması tercih edilir. Fakat bu durum eviricilerde yüksek anahtarlama kayıplarına neden olur. Bu anahtarlama kayıplarını belirli bir seviyede tutmak için çıkış frekansında taşıyıcı oranı küçültülür. Böylece $\mathrm{M}_{\mathrm{o}} \leq 1$ ve $\mathrm{M}_{\mathrm{f}}=21$ olduğu denge noktası sinır değeri elde edilir (Kocalmış Bilhan, 2012).

\section{Uzay vektör darbe genişlik modülasyonu}

Mikroişlemcilerde yaşanan gelişmelerle beraber DGM teknikleri arasında en önemlilerden birisi haline gelmiştir. Bu tekniği önemli kılan unsurlar; dijital işlemcilerle kolayca uygulanabilir olması, anahtarlama kayıplarını önemli ölçüde azaltması, çıkış gerilimindeki harmonik bileşenleri minimize etmesi, diğer modülasyon yöntemleri ile kıyaslandığında daha yüksek genlik modülasyon faktörleri elde edilmesidir (Rathnakumar, 2005).

UVDGM yönteminin amac1, toplam harmonik bozunumu ve anahtarlama kayıplarını en düşük seviye indirgeyerek çıkış dalga formunu sinüzoidal

4.Adım: Her bir sektör için $\mathrm{T}_{\mathrm{a}}, \mathrm{T}_{\mathrm{b}}$ ve $\mathrm{T}_{\mathrm{o}}$ anahtarlama konum süreleri hesaplanır.

5.Adım:Hesaplanan sürelere uygun olarak anahtarlama sinyalleri üretilir.

1. Adım: Eviricinin üretmesi gereken $V_{a}, V_{b}$ ve $\mathrm{V}_{\mathrm{c}}$ referans gerilimler Denklem (4)'de verilen Clarke dönüşümü kullanılarak Şekil 1.(a)'da gösterildiği gibi $\mathrm{V}_{\mathrm{d}}, \mathrm{V}_{\mathrm{q}}$ bileşenlerine dönüştürülür. Referans gerilim vektörünün genliği ve açısı ise sırası ile Denklem (5) ve (6) yardımıyla bulunur (Eskin, 2012). 


$$
\begin{aligned}
& {\left[\begin{array}{l}
V_{d} \\
V_{q}
\end{array}\right]=\frac{2}{3}\left[\begin{array}{ccc}
1 & -1 / 2 & -1 / 2 \\
0 & \sqrt{3} / 2 & -\sqrt{3} / 2
\end{array}\right]\left[\begin{array}{l}
V_{a} \\
V_{b} \\
V_{c}
\end{array}\right]} \\
& V_{r e f}=\sqrt{V_{d}^{2}+V_{q}^{2}} \\
& \theta=\arctan V_{q} / V_{d}
\end{aligned}
$$

Gerilim vektör uzayı için sektörler ve bölgeleri Şekil 1.(b)'de verilmiştir.

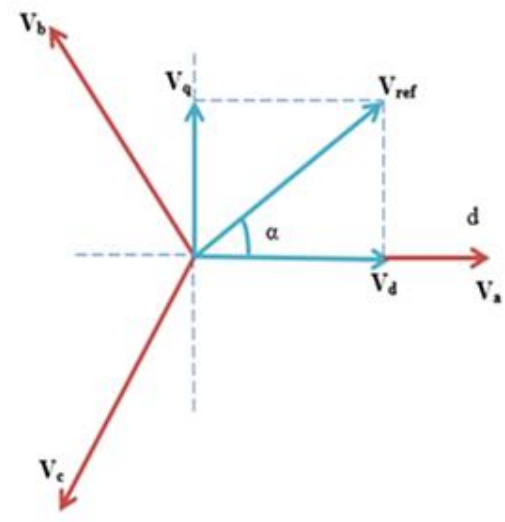

(a)

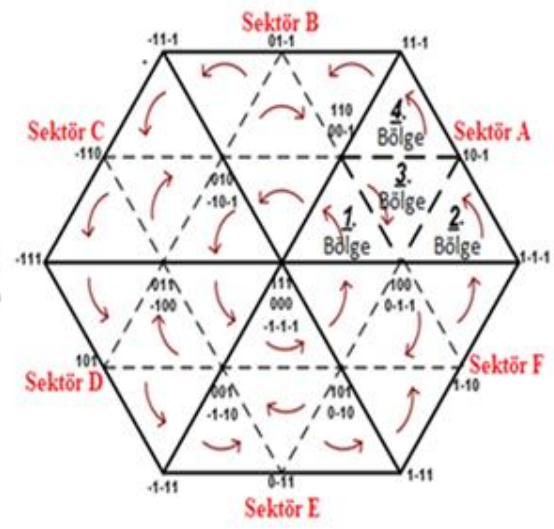

(b)

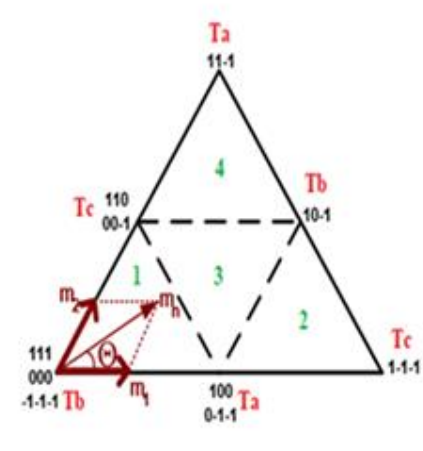

(c)

Şekil 1. (a) Gerilim uzay vektörü ve bileşenleri (b) Gerilim vektör uzayı için sektörler ve bölgeleri

(c) Sektör A'ya ait uzay vektör diyagramı

Tablo 1. Açı değerlerine göre sektör belirlenmesi ile $m_{1}$ ve $m_{2}$ değerlerine göre bölge tespiti

\begin{tabular}{|c|l|l|l|l|l|}
\hline AÇI ( $\boldsymbol{\theta})$ & $\begin{array}{l}\text { V } \\
\text { ref' }{ }^{\prime} \text { in } \\
\text { Bulunduğu Sektör }\end{array}$ & $\begin{array}{l}\text { Bölge } \\
\text { Numarası }\end{array}$ & $\mathbf{m}_{\mathbf{1}}$ & $\mathbf{m}_{\mathbf{2}}$ & $\mathbf{m}_{\mathbf{1}}+\mathbf{m}_{\mathbf{2}}$ \\
\hline $0^{\circ} \leq \theta<60^{\circ}$ & Sektör A & 1. Bölge & $<0.5$ & $<0.5$ & $<0.5$ \\
\hline $60^{\circ} \leq \theta<120^{\circ}$ & Sektör B & 2. Bölge & $>0.5$ & - & - \\
\hline $120^{\circ} \leq \theta<180^{\circ}$ & Sektör C & 3. Bölge & $<0.5$ & $<0.5$ & $>0.5$ \\
\hline $180^{\circ} \leq \theta<240^{\circ}$ & Sektör D & 4. Bölge & - & $>0.5$ & - \\
\hline $240^{\circ} \leq \theta<300^{\circ}$ & Sektör E & & & & \\
\hline $300^{\circ} \leq \theta<360^{\circ}$ & Sektör F & & & & \\
\hline
\end{tabular}

3. Adım: Sektör A içerisinde bulunuyorsa, artık hangi bölgenin içerisinde bulunduğu belirlenir. Sektör A'ya ait uzay vektör diyagramı Şekil 1.(c)'de verilmiştir.

Şekil 1.(c)'de görüldüğü üzere gerilim vektörünün dört bölgeden hangisinde olduğunun tespit edilmesi gerekir. Bunun için de gerilim vektörü matematiksel denklemler yardımıyla $m_{1}$ ve $m_{2}$ şeklinde bileşenlerine ayrılarak hesaplanır. Buradan $\mathrm{m}_{1}$ ve $\mathrm{m}_{2}$ 'nin değerlerine bakarak Sektör A için gerilim vektörünün hangi bölgede olduğu tespiti Tablo 1 yardımıyla bulunur. Diğer sektörler için de $\mathrm{m}_{1}$ ve $\mathrm{m}_{2}$ hesapları yap1larak bölge tespiti gerçekleştirilir. 
4. Adım: Her bir sektördeki her bir bölgede farklı anahtarlama sayıları ve sıraları olacağı için her bölge için ayrı ayrı anahtarlama sürelerinin hesaplanması gerekir. Örneğin Sektör A için 1. Bölge ele alınırsa toplamda 7 anahtarlama durumu söz konusudur ve bu anahtarlama sirasi $T_{b}, T_{c}$ ve $T_{a}$ şeklinde olacaktır. Eğer anahtarlama konum süreleri hesaplanmak istenirse süre hesabı yapılır.

$$
\begin{aligned}
& V_{\text {ref }} \cdot T_{s}=V_{a} \cdot T_{a}+V_{b} \cdot T_{b}+V_{c} \cdot T_{c} \\
& T_{s}=T_{a}+T_{b}+T_{c}
\end{aligned}
$$

Denklem (8) ve $\mathrm{V}_{\mathrm{a}}, \mathrm{V}_{\mathrm{b}}$ ve $\mathrm{V}_{\mathrm{c}}$ gerilimleri yardımıyla her sektörün her bölgesine ait anahtarlama süreleri hesaplanır. UVDGM ile ilgili formül ve bilgilerin detayları literatürde mevcuttur (Arslanoğlu, 2019).

5. Adım: Gerilim vektörünün hangi sektörde ve hangi bölgede olduğunun tespitinden sonra $T_{a}, T_{b}$ ve $\mathrm{T}_{\mathrm{o}}$ anahtarlama konum süreleri hesaplanır. Hesaplanan bu değerlere göre uygun anahtarlama sıraları seçilir ve uygulanır (Kocalmış, 2005).

Bu karșılaştırmalarda akım, gerilim sinyali genlikleri ve harmonikleri gibi bazı sonuçlar incelenmiştir.

\section{İki Seviyeli SDGM Eviricinin Benzetim Modeli}

SDGM kontrol yöntemi kullanılarak R / R-L yüklü iki seviyeli bir eviricinin benzetimi Şekil 2.(a)'da verilmiştir. Bu teknikte şu adımlar izlenmektedir:

1. Farklı genlik ve frekanstaki sinüzoidal referans işareti daha yüksek frekanslı üçgen dalga taşıyıcı işaretle karşıllaştırılması yapılır.

2. Olușan kesișim noktalarıyla anahtarlama elemanlarının anahtarlama süreleri ve güç anahtarları için gerekli olan tetikleme sinyali elde edilerek uygulanır.

\section{Üç Seviyeli UVDGM Eviricinin Benzetim Modeli}

Üç seviyeli UVDGM kontrol yöntemi kullanılarak R / R-L yüklü bir eviricinin benzetimi yapılmıştır. Şekil 2.(b)'de R / R-L yüklü üç seviyeli eviricinin MATLAB/Simulink modeli görülmektedir.

MATLAB/Simulink benzetimin yapılmasında şu adımlar izlenir;

1. Gerilim vektörünün hangi sektöre düştüğü tespit edilir.

\section{BULGULAR}

Şebekeden bağımsız iki seviyeli SDGM ile üç seviyeli UVDGM kontrol yöntemi kullanılarak Tablo 2 'de verilen parametreler yardımıyla benzetimler gerçekleştirilmiştir.

Benzetimler neticesinde SDGM ve UVDGM için çıkış gerilimlerinin Tablo 2'deki parametreler kullanılarak hesaplanırsa teorik olarak aşağıdaki gibi bir değerde olması beklenir.

$$
\begin{aligned}
& V_{c l k l_{S D G M}}=M_{i} \cdot \frac{V_{D A}}{2}=0.8 \cdot \frac{717.817}{2} \\
& =311.126 \mathrm{~V} \text { (Akmaz ve diğerleri, 2016). } \\
& V_{\text {çlk } \text { S }_{U V D G M}}=0.707 \cdot M_{i} \cdot V_{D A} \\
& =0.707 \cdot 0.8 \cdot 550.082 \\
& =311.126 \mathrm{~V} \text { (Deniz, 2010). }
\end{aligned}
$$

Benzetimlerde daha etkili bir analiz sağlanması için ilk olarak rezistif yük kullanılmış ve iki yöntem karşılaştırılmıştır. Daha sonra rezistif-endüktif yük benzetimler için kullanılmış ve iki yöntem tekrar karşılaştırılmıştır.

2. Vektörün sektör içinde hangi bölgeye düştüğü tespit edilir

3. Anahtarlama süreleri hesaplanır.

4. Her bir sektörün her bir bölgesi için anahtarların anahtarlama sıraları belirlenir ve uygulanir.

\section{SDGM ve UVDGM Yöntemlerinin Özellikleri}

SDGM; Asenkron veya Senkron, açık çevrim, taşıyıcı tabanlıdır, Lineer modülasyon bölgesi düşüktür $(0<\mathrm{m}<0.785)$, üçüncü harmonik ilave edilerek 0,907 ye artırılabilir.), Aşırı modilasyon aralığı doğrusal olmayan özellik gösterir, En düşük hamonik dalgalanmalar $0<\mathrm{m}<0,4$ aralığındadır, uygulanması kolaydır, Analog olarak uygulanır (düzenli örnekleme yöntemi ile dijital olarak uygulanabilir.)

UVDGM; Asenkron veya senkron açık çevrim, taşıyıcı tabanlı olmayan bir yöntemdir, Nötrü izoleli üz fazlı eviricilerde çok iyidir, Lineer modülasyon bölgesi geniştir. $(0<\mathrm{m}<0.907)$, Aşırı modülasyonda kare dalgaya kadar kolayca doğrusallaştırma olanağ 1 vardır, En düşük hamonik dalgalanmalar lineer bölgede meydana gelir, Yoğun ve karmaşık hesaplamalar içerir, Mikroişlemci ve DSP gerektirir. (dijital bir yöntemdir.) (Asker ve ark., 2009) 
Tablo 2. R/R-L yüklü SDGM ve UVDGM için benzetim parametreleri

\begin{tabular}{|l|l|}
\hline Evirici Giriş Gerilimi ( $\left.\mathrm{V}_{\mathrm{DA}}\right)$ & $\begin{array}{l}\mathrm{SDGM}=777.817 \mathrm{~V} \\
\mathrm{UVDGM}=550.082 \mathrm{~V}\end{array}$ \\
\hline Evirici Çıkış Gerilimi ( $\left.\mathrm{V}_{\mathrm{AA}}\right)$ & $\begin{array}{l}\mathrm{SDGM}=311 \mathrm{~V} \\
\mathrm{UVDGM}=311 \mathrm{~V}\end{array}$ \\
\hline Şebeke Frekansı & $50 \mathrm{~Hz}$ \\
\hline Transformatör & $4.5 \mathrm{KVA}$ \\
\hline Filtre & $200 \mathrm{~W}($ aktif $), 30.86 \mu \mathrm{F}, 380 \mathrm{~V}_{\mathrm{tt}}(\mathrm{rms})$ \\
\hline Modülasyon İndeksi $\left(\mathrm{M}_{\mathrm{i}}\right)$ & 0.8 \\
\hline Yük: R için & $4 \mathrm{KW}($ Omik) \\
\hline Yük: R-L için & $4 \mathrm{KW}($ Omik), 4.775 H, 380V $\mathrm{tt}(\mathrm{rms})$ \\
\hline
\end{tabular}

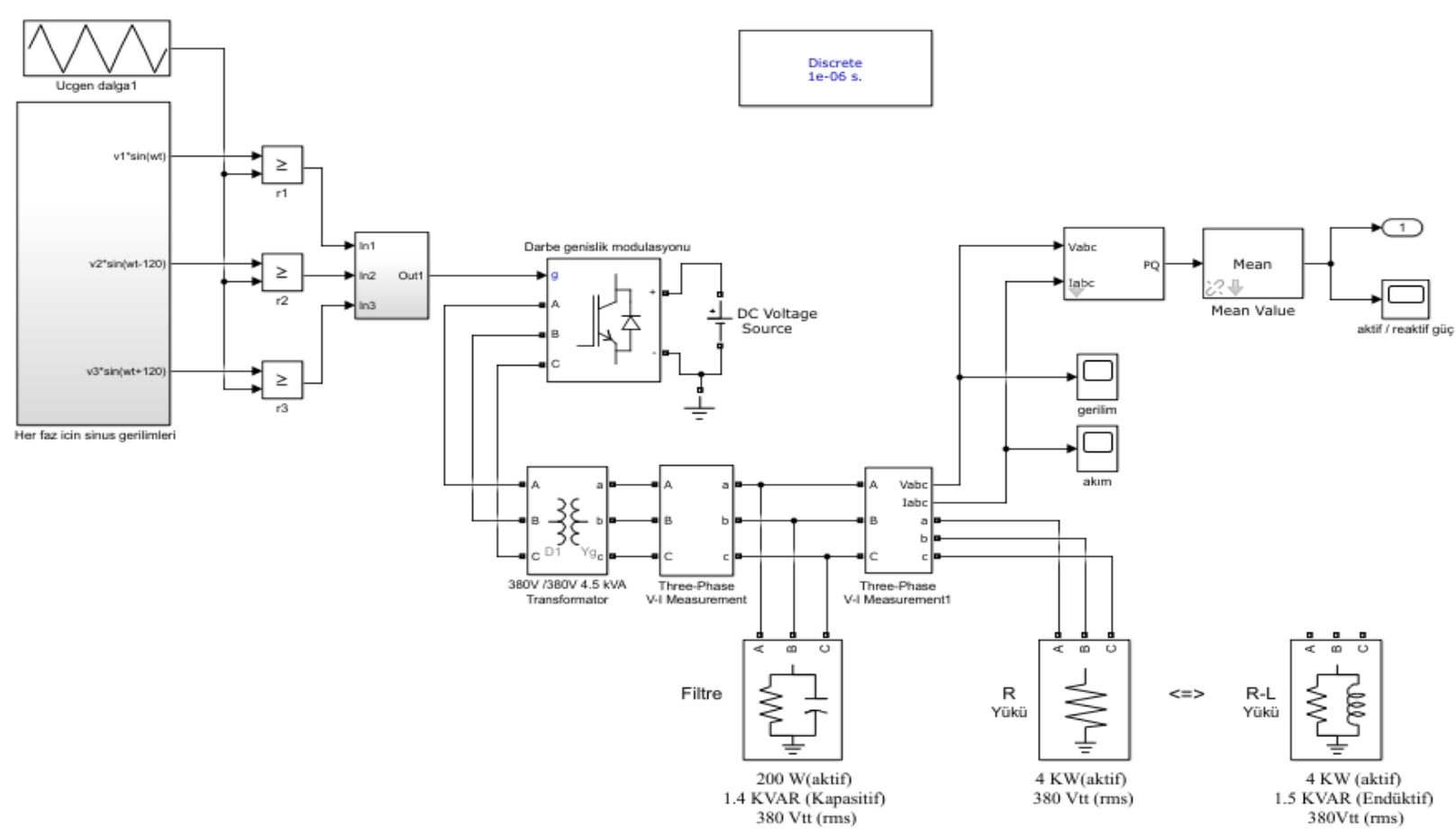

(a) 


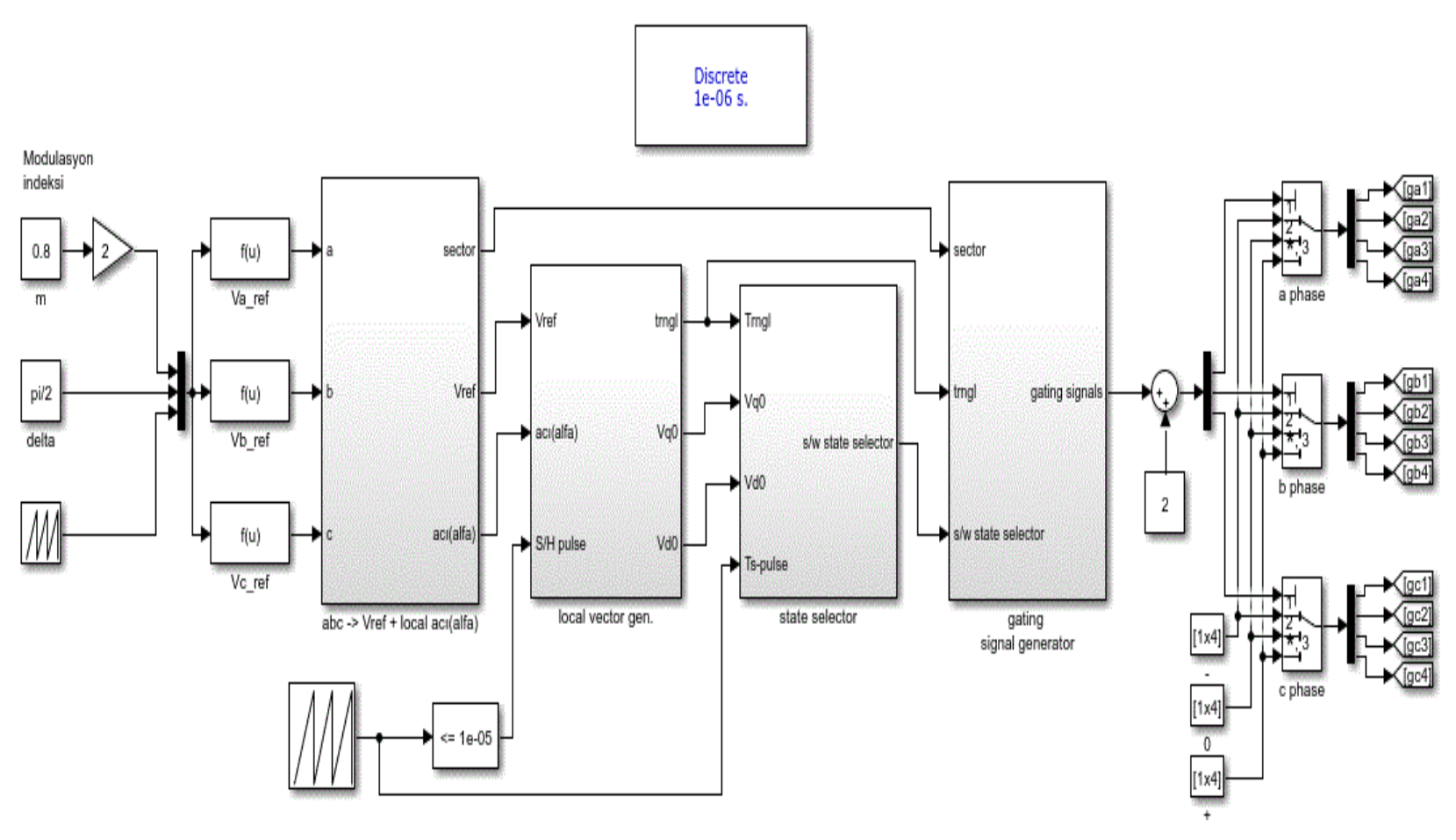

(b)

Şekil 2. (a) R / R-L yüklü iki seviyeli SDGM eviricinin benzetimi

(b) R / R-L yüklü üç seviyeli UVDGM eviricisinin giriş sinyallerinin üretildiği MATLAB/Simulink benzetim modeli

\section{Benzetim Sonuçları}

$\mathrm{Bu}$ bölümde her iki yöntemin farklı yüklerde kullanılması sonucu elde edilen benzerim sonuçları verilmiştir.

A) Rezistif yük kullanılması sonucu iki yöntemin karşılaştırılması

\section{1) İki Seviyeli SDGM Tekniğinin Benzetim Sonuçları}

$\mathrm{R}$ yüklü iki seviyeli SDGM'nin benzetim sonuçlarından $\quad I_{a}, I_{b}, I_{c}$ akım dalga şekilleri Şekil 3.(a)'da; bu akımların harmonik spektrumu ise Şekil 3.(b)'de verilmiştir. $V_{a}, V_{b}, V_{c}$ gerilim dalga şekilleri Şekil 3.(c)'de; bu gerilimlerin harmonik spektrumu ise Şekil 3.(d)'de verilmiştir. Aktif ve reaktif güce ait dalga şekli ise Şekil 3.(e)'de verilmiştir. 


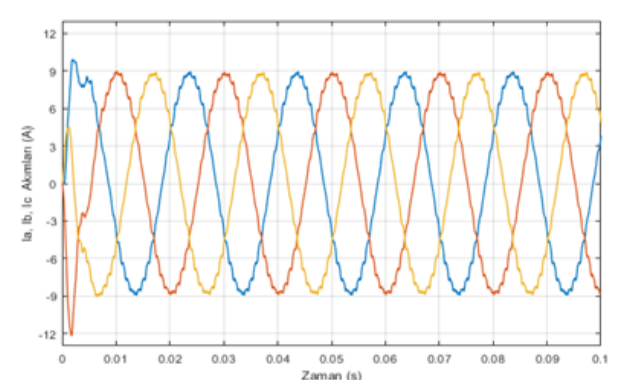

(a)

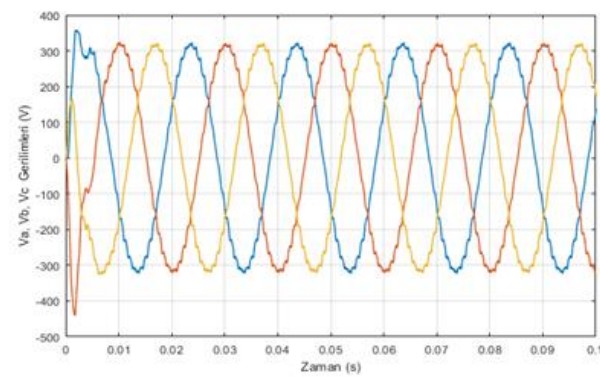

(c)

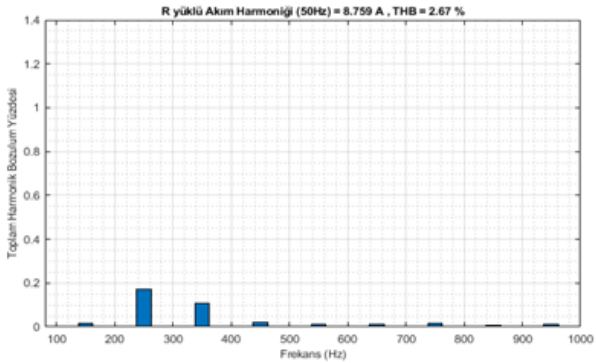

(b)

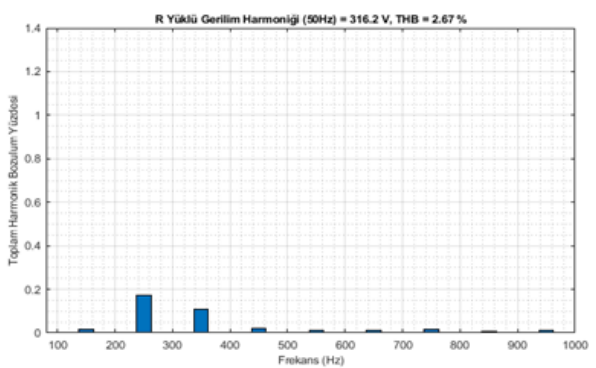

(d)

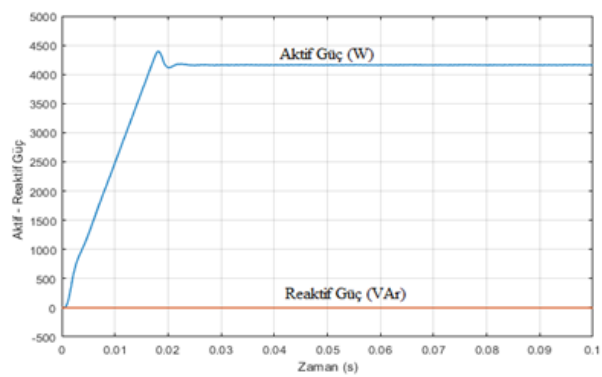

(e)

Şekil 3. (a) $M_{i}$ aynı $V_{D A}$ gerilimi farklı olan R yüklü SDGM'nin $I_{a}, I_{b}, I_{c}$ akımlarının akım dalga şekilleri

(b) $\mathrm{M}_{\mathrm{i}}$ aynı $\mathrm{V}_{\mathrm{DA}}$ gerilimi farklı olan $\mathrm{R}$ yüklü SDGM'nin $\mathrm{I}_{\mathrm{a}}, \mathrm{I}_{\mathrm{b}}, \mathrm{I}_{\mathrm{c}}$ akımlarının harmonik spektrumu (c) $M_{i}$ aynı $V_{D A}$ gerilimi farklı olan $R$ yüklü SDGM'nin $V_{a}, V_{b}, V_{c}$ gerilim dalga şekilleri

(d) $\mathrm{M}_{\mathrm{i}}$ aynı $\mathrm{V}_{\mathrm{DA}}$ gerilimi farklı olan $\mathrm{R}$ yüklü SDGM'nin $\mathrm{V}_{\mathrm{a}}, \mathrm{V}_{\mathrm{b}}, \mathrm{V}_{\mathrm{c}}$ gerilimlerin harmonik spektrumları

(e) $M_{i}$ aynı $V_{D A}$ gerilimi farklı olan R yüklü SDGM'nin aktif ve reaktif güç dalga şekli

\section{2) Üç Seviyeli UVGDM Eviricinin Benzetim}

\section{Sonuçları}

R yüklü iki seviyeli üç seviyeli UVDGM'nin benzetim sonuçlarından $\mathrm{I}_{\mathrm{a}}, \mathrm{I}_{\mathrm{b}}, \mathrm{I}_{\mathrm{c}}$ akım dalga şekilleri Sekil 4.(a)'da; bu akımların harmonik spektrumu ise Şekil 4.(b)'de verilmiştir. $V_{a}, V_{b}, V_{c}$ gerilim dalga

şekilleri Şekil 4.(c)'de; bu gerilimlerin harmonik spektrumu ise şekil 4.(d)'de verilmiştir. Aktif ve reaktif güce ait dalga şekli ise Şekil 4.(e)'de verilmiştir. 


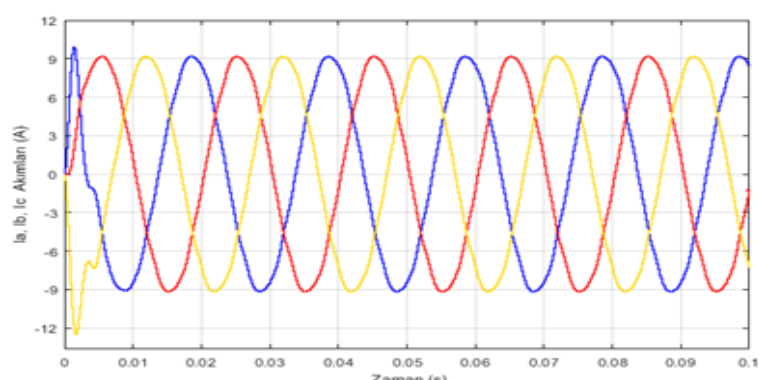

(a)

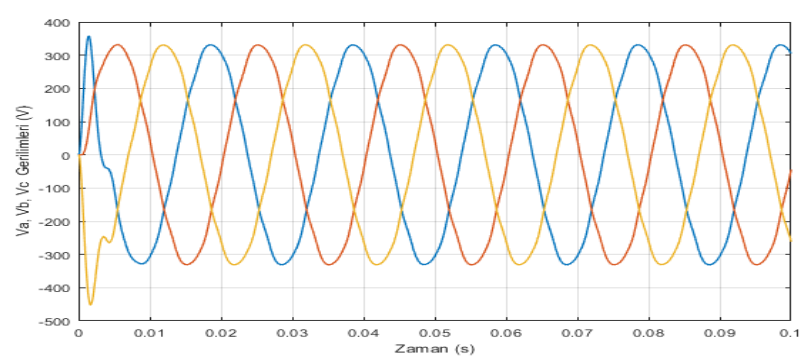

(c)

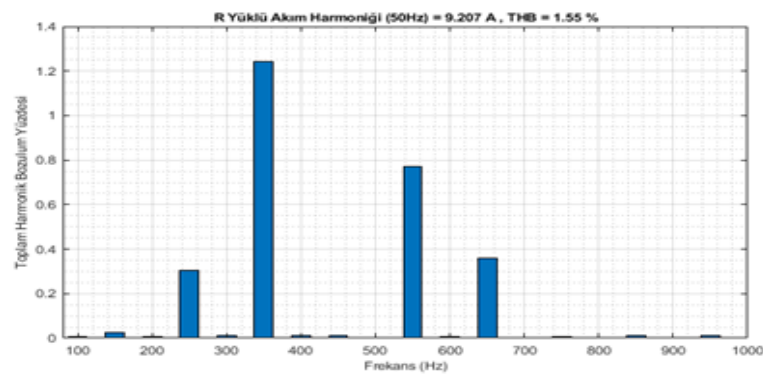

(b)

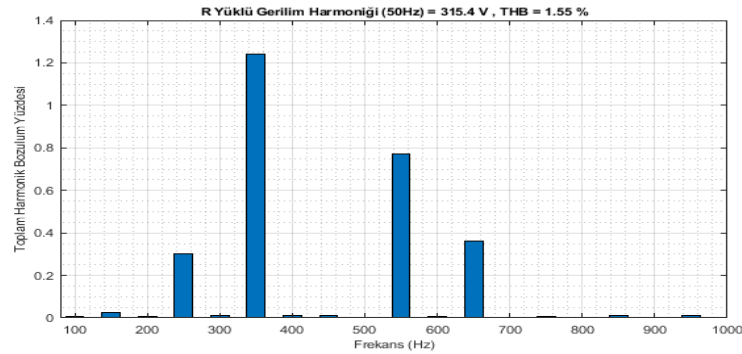

(d)

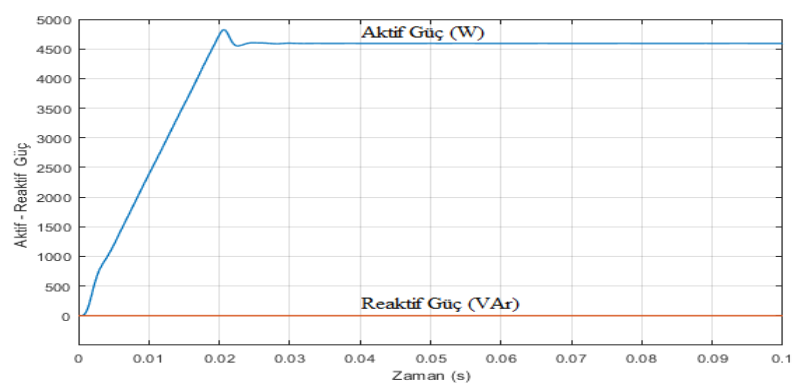

(e)

Şekil 4. (a) $M_{i}$ aynı $V_{D A}$ gerilimi farklı olan $R$ yüklü UVDGM'nin $I_{a}, I_{b}, I_{c}$ akımlarının akım dalga şekilleri (b) $M_{\mathrm{i}}$ aynı $\mathrm{V}_{\mathrm{DA}}$ gerilimi farklı olan $\mathrm{R}$ yüklü UVDGM'nin $\mathrm{I}_{\mathrm{a}}, \mathrm{I}_{\mathrm{b}}, \mathrm{I}_{\mathrm{c}}$ akımlarının harmonik spektrumu (c) $\mathrm{M}_{\mathrm{i}}$ aynı $\mathrm{V}_{\mathrm{DA}}$ gerilimi farklı olan $\mathrm{R}$ yüklü UVDGM'nin $\mathrm{V}_{\mathrm{a}}, \mathrm{V}_{\mathrm{b}}, \mathrm{V}_{\mathrm{c}}$ gerilim dalga şekilleri (d) $\mathrm{M}_{\mathrm{i}}$ aynı $\mathrm{V}_{\mathrm{DA}}$ gerilimi farklı olan $\mathrm{R}$ yüklü UVDGM'nin $\mathrm{V}_{\mathrm{a}}, \mathrm{V}_{\mathrm{b}}, \mathrm{V}_{\mathrm{c}}$ gerilimlerin harmonik spektrumları (e) $M_{\mathrm{i}}$ aynı $\mathrm{V}_{\mathrm{DA}}$ gerilimi farklı olan $\mathrm{R}$ yüklü UVDGM'nin aktif ve reaktif güç dalga şekli

\section{B) Rezistif-endüktif yük kullanılması sonucu iki yöntemin karşılaştırılması}

1) İki Seviyeli SDGM Tekniğinin Benzetim Sonuçları

SDGM'nin benzetim sonuçlarından $\mathrm{I}_{\mathrm{a}}, \mathrm{I}_{\mathrm{b}}, \mathrm{I}_{\mathrm{c}}$ akım dalga şekilleri Şekil 5.(a)'da; bu akımların harmonik spektrumu ise Şekil 5.(b)'de verilmiştir. $\mathrm{V}_{\mathrm{a}}, \mathrm{V}_{\mathrm{b}}, \mathrm{V}_{\mathrm{c}}$ gerilim dalga șekilleri Şekil 5.(c)'de; bu gerilimlerin harmonik spektrumu ise Şekil 5.(d)'de verilmiştir. Aktif ve reaktif güce ait dalga şekli Şekil 5.(e)'de verilmiștir. 


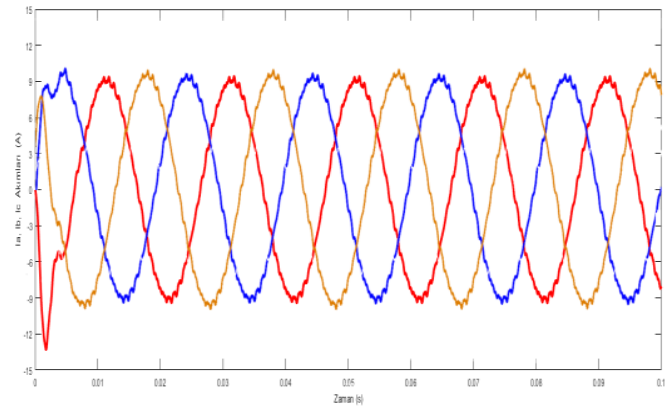

(a)

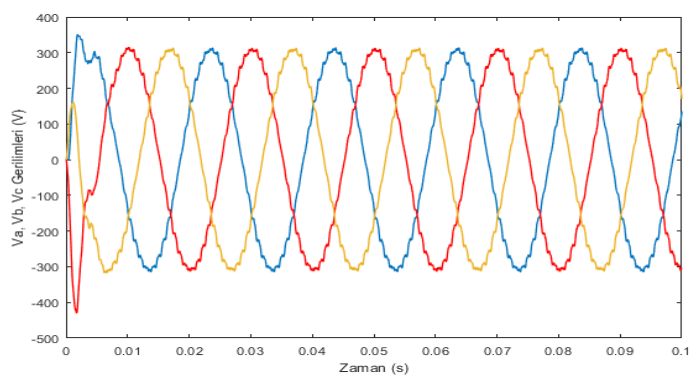

(c)

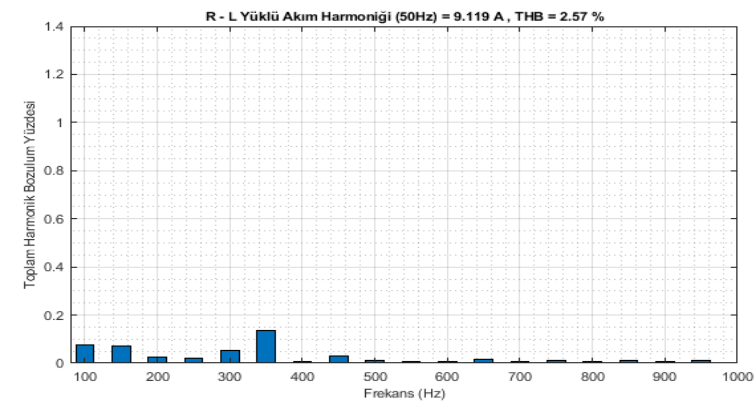

(b)

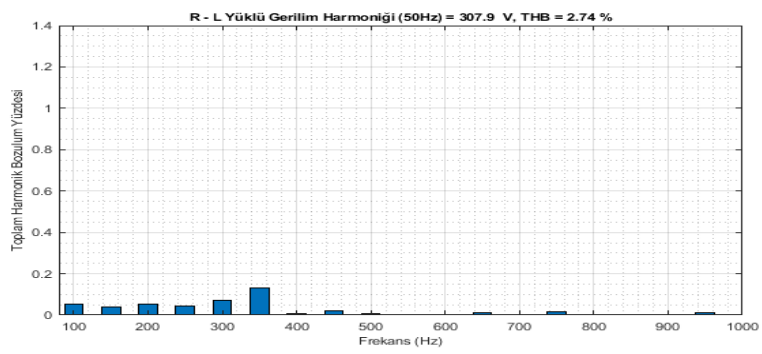

(d)

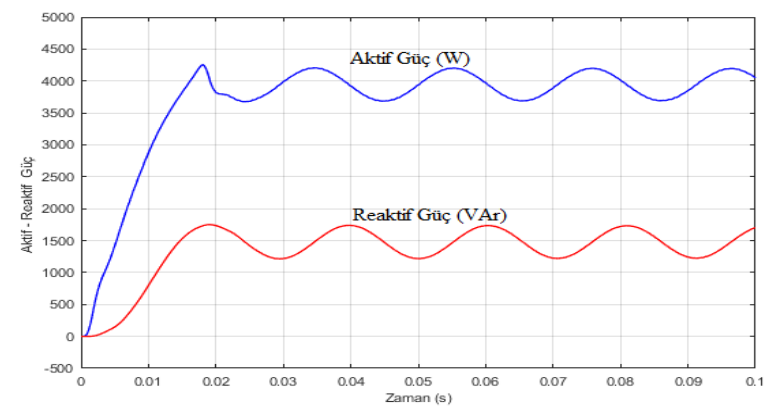

(e)

Şekil 5. (a) $M_{i}$ aynı $V_{D A}$ gerilimi farklı olan R-L yüklü SDGM'nin $I_{a}, I_{b}, I_{c}$ akımlarının akım dalga şekilleri (b) $M_{\mathrm{i}}$ aynı $V_{\mathrm{DA}}$ gerilimi farklı olan R-L yüklü SDGM'nin $\mathrm{I}_{\mathrm{a}}, \mathrm{I}_{\mathrm{b}}, \mathrm{I}_{\mathrm{c}}$ akımlarının harmonik spektrumu (c) $\mathrm{M}_{\mathrm{i}}$ aynı VDA gerilimi farklı olan R-L yüklü SDGM'nin $\mathrm{V}_{\mathrm{a}}, \mathrm{V}_{\mathrm{b}}, \mathrm{V}_{\mathrm{c}}$ gerilim dalga şekilleri (d) $\mathrm{M}_{\mathrm{i}}$ aynı $\mathrm{V}_{\mathrm{DA}}$ gerilimi farklı olan R-L yüklü SDGM'nin $\mathrm{V}_{\mathrm{a}}, \mathrm{V}_{\mathrm{b}}, \mathrm{V}_{\mathrm{c}}$ gerilimlerin harmonik spektrumları (e) $M_{i}$ aynı $V_{D A}$ gerilimi farklı olan R-L yüklü SDGM'nin aktif ve reaktif güç dalga şekli

\section{2) Üç Seviyeli UVDGM Tekniğinin Benzetim}

\section{Sonuçları}

UVDGM eviricisinin benzetim sonucu

Tablo 2'deki parametreler kullanılarak elde edilmiştir. $\mathrm{Bu}$ parametrelerden $\mathrm{M}_{\mathrm{i}}$ aynı $\mathrm{V}_{\mathrm{DA}}$ hat geriliminin ise farklı olduğu R-L yüklü UVDGM'nin benzetim sonuçlarından $\mathrm{I}_{\mathrm{a}}, \mathrm{I}_{\mathrm{b}}, \mathrm{I}_{\mathrm{c}}$ akım dalga şekilleri $\mathrm{V}_{\mathrm{a}}, \mathrm{V}_{\mathrm{b}}, \mathrm{V}_{\mathrm{c}}$ gerilim dalga şekilleri Şekil 6.(c)'de; bu gerilimlerin harmonik spektrumu ise Şekil 6.(d)'de verilmiştir. Aktif ve reaktif güce ait dalga şekli ise Şekil 6.(e)'de verilmiştir. Şekil 6.(b)'de verilmiştir. 


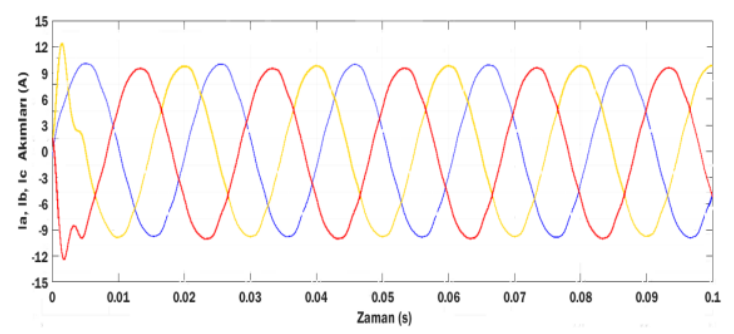

(a)

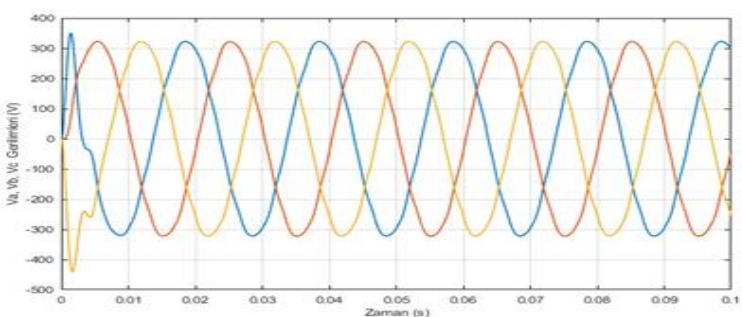

(c)

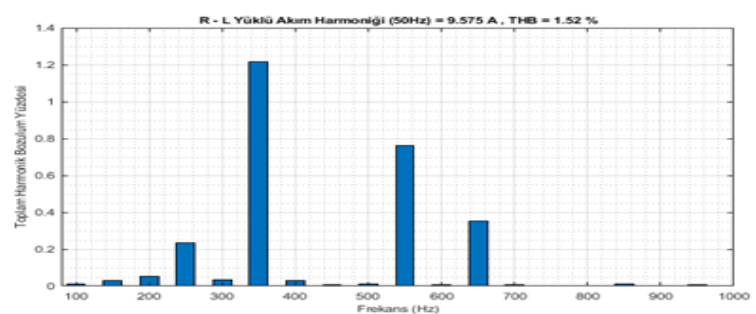

(b)

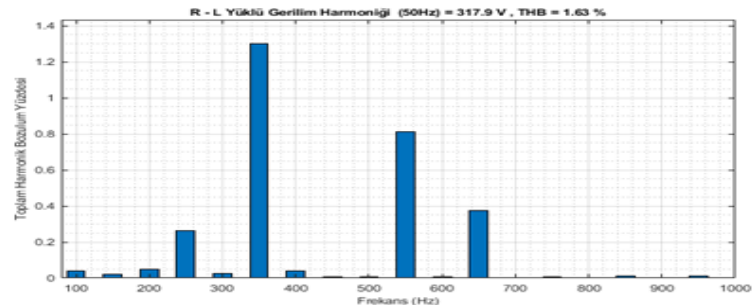

(d)

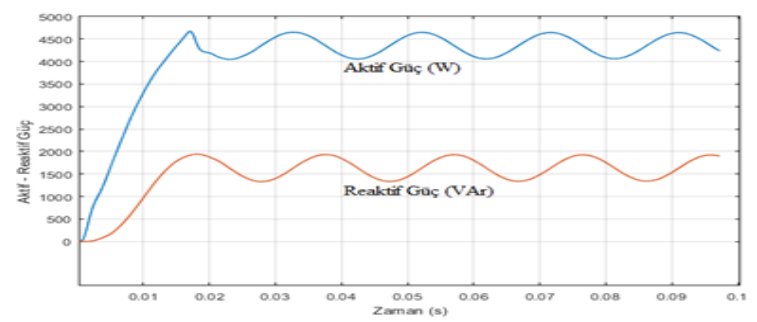

(e)

Şekil 6. (a) $M_{i}$ aynı $V_{D A}$ gerilimi farklı olan R-L yüklü UVDGM'nin $I_{a}, I_{b}, I_{c}$ akımlarının akım dalga şekilleri (b) $\mathrm{M}_{\mathrm{i}}$ aynı $\mathrm{V}_{\mathrm{DA}}$ gerilimi farklı olan R-L yüklü UVDGM'nin $\mathrm{I}_{\mathrm{a}}, \mathrm{I}_{\mathrm{b}}, \mathrm{I}_{\mathrm{c}}$ akımlarının harmonik spektrumu (c) $M_{i}$ aynı $V_{D A}$ gerilimi farklı olan R-L yüklü UVDGM'nin $V_{a}, V_{b}, V_{c}$ gerilim dalga şekilleri

(d) $\mathrm{M}_{\mathrm{i}}$ aynı $\mathrm{V}_{\mathrm{DA}}$ gerilimi farklı olan R-L yüklü UVDGM'nin $\mathrm{V}_{\mathrm{a}}, \mathrm{V}_{\mathrm{b}}, \mathrm{V}_{\mathrm{c}}$ gerilimlerin harmonik spektrumları (e) $\mathrm{M}_{\mathrm{i}}$ aynı $\mathrm{V}_{\mathrm{DA}}$ gerilimi farklı olan R-L yüklü UVDGM'nin aktif ve reaktif güç dalga şekli

Elde edilen sonuçlara ait sayısal değerler Tablo 3'te verilmiştir.

Tablodaki verilerden yola çıkarak;

1. Aynı çıkış gerilimi elde etmek için UVDGM tekniğinde SDGM tekniğine kıyasla daha küçük $\mathrm{V}_{\mathrm{DA}}$ hat gerilimi kullanılır. Diğer bir ifadeyle UVDGM tekniğinde daha düşük giriş gerilimi kullanılarak aynı çıkış gerilimi elde edilir.

2. UVDGM tekniği SDGM tekniğine kıyasla daha düşük harmonik bozunuma sahiptir.
3. Teorik olarak hesaplanan çıkış gerilimi ile benzetimler neticesinde elde edilen çıkış gerilimleri birbirine yakındır.

4. Tablo 3'te R / R-L yüklü SDGM ve UVDGM benzetimi sonucunda elde edilen akım ve gerilime ait toplam harmonik bozulma seviyesinin uluslararas standartlarda belirtilen değer olan akım için \%3, gerilim için \%5'in atında olduğu görülmektedir. Böylece yapılan benzetim çalışmasının sonucunun doğru ve standartları sağladığı da tespit edilmiştir.

Tablo 3. $M_{i}$ aynı $V_{D A}$ gerilimleri farklı olan $R / R$-L yükleri için benzetim sonuçları 


\begin{tabular}{|c|c|c|c|c|}
\hline \multicolumn{5}{|c|}{ R Yüklü Benzetim Sonuçları } \\
\hline & \multicolumn{2}{|c|}{ SDGM } & \multicolumn{2}{|c|}{ UVDGM } \\
\hline Giriş gerilimi $\left(\mathrm{V}_{\mathrm{DA}}\right)$ & \multicolumn{2}{|c|}{$777.817 \mathrm{~V}$} & \multicolumn{2}{|c|}{$550.082 \mathrm{~V}$} \\
\hline \multirow{2}{*}{ Çıkış gerilimi (Etkin değer) } & Teorik Sonuç & Benzetim Sonucu & Teorik Sonuç & Benzetim Sonucu \\
\hline & $311.126 \mathrm{~V}$ & $316.2 \mathrm{~V}$ & $311.126 \mathrm{~V}$ & $315.4 \mathrm{~V}$ \\
\hline Yük Akımı \% (THB) & \multicolumn{2}{|c|}{$\% 2.67$} & \multicolumn{2}{|c|}{$\% 1.55$} \\
\hline Yük Gerilimi \% (THB) & \multicolumn{2}{|c|}{$\% 2.67$} & \multicolumn{2}{|c|}{$\% 1.55$} \\
\hline \multicolumn{5}{|c|}{ R - L Yüklü Benzetim Sonuçları } \\
\hline & \multicolumn{2}{|c|}{ SDGM } & \multicolumn{2}{|c|}{ UVDGM } \\
\hline Giriş gerilimi $\left(\mathrm{V}_{\mathrm{DA}}\right)$ & \multicolumn{2}{|c|}{$777.817 \mathrm{~V}$} & \multicolumn{2}{|c|}{$550.082 \mathrm{~V}$} \\
\hline \multirow{2}{*}{ Çıkış gerilimi (Etkin değer) } & Teorik Sonuç & Benzetim Sonucu & Teorik Sonuç & Benzetim Sonucu \\
\hline & $311.126 \mathrm{~V}$ & $307.9 \mathrm{~V}$ & $311.126 \mathrm{~V}$ & $317.9 \mathrm{~V}$ \\
\hline Yük Akımı \% (THB) & \multicolumn{2}{|c|}{$\% 2.57$} & \multicolumn{2}{|c|}{$\% 152$} \\
\hline Yük Gerilimi \% (THB) & \multicolumn{2}{|c|}{$\% 2.74$} & \multicolumn{2}{|c|}{$\% 1.63$} \\
\hline
\end{tabular}

\section{SONUÇLAR VE TARTIŞMA}

Darbe genişlik modülasyon teknikleri kıyaslandığında bu tekniklerin birbirlerine karșı çeşitli üstünlükleri vardır. Bu teknikler içerisinde en yaygın olarak kullanılan iki teknik karşımıza çıkmaktadır. Biri SDGM tekniği, diğeri ise UVDGM tekniğidir.

Mikroişlemcilerde yaşanan gelişmeler ile beraber yeni darbe genişlik modülasyon teknikleri geliştirilmiştir. UVDGM tekniği, bu gelişmelerin bir ürünüdür. UVDGM ile çıkış gerilimi istenilen frekans ve genlikte ayarlanmakta ve mikroişlemciler yardımıyla oldukça kolay bir şekilde uygulanabilmektedir.

$\mathrm{Bu}$ çalışmada şebekeden bağımsız iki seviyeli SDGM ile üç seviyeli UVDGM eviricilerinin MATLAB/Simulink benzetim modeli gerçekleştirilmiştir.

Tablo 3'te verilen benzetim sonuçları incelendiğinde; UVDGM eviricinin SDGM'ye göre daha az harmonik bozuluma sahip olduğu, daha düşük hat gerilimi ile aynı çıkış gerilimi elde edildiği görülmektedir. UVDGM eviricisine ait bu sonuçlar göz önüne alındığında UVDGM tekniğinin SDGM tekniğine nazaran daha iyi bir performans gösterdiği yapılan benzetimler neticesinde tespit edilmiştir. Ayrıca, teorik hesaplamalarla benzetim sonuçlarının da birbirine yakın olduğu gözlenmiştir. Bu durum da sistemin doğru sonuçlar gösterdiğini teyit etmektedir.

SDGM ve UVDGM evirici türlerinin geniş bir uygulama alanı olduğundan gerek akademik alanda gerek de endüstriyel alanda AR-GE çalışmaları sürekli yapılmaktadır. $\mathrm{Bu}$ yüzden bu alan popülerliğini yitirmeyeceği gibi bu alanda yapılacak daha optimum özellikli evirici ciddi bir kazanç sağlayacaktır. Dolayısıyla gelişmeleri takip etmek ve daha optimum özellikli evirici tasarımı gerçekleştirmek gittikçe önem kazanmaktadır.

\section{TEŞEKKÜR}

Bu makale birinci yazarın yüksek lisans tezinden türetilmiştir.

\section{ÇIKAR ÇATIŞMASI BEYANI}

Yazarlar bu çalışmasında herhangi bir şekilde çıkar çatışması olmadığını beyan eder.

\section{ARAŞTIRMA VE YAYIN ETİĞİ BEYANI}

Yazarlar bu çalışmasında araştırma ve yayın etiğine uyulduğunu beyan eder. 


\section{KAYNAKLAR}

Akmaz, D., Mamiş, M.S., Gülan, H., Şeker, B. (2016). İki farklı darbe genişlik modülasyonlu evirici tasarımı ve bu eviricilerin akılllı şebekeler için kıyaslanması. 1st International Mediterranean Science and Engineering Congress (IMSEC), Çukurova Üniversitesi, Adana / Türkiye Ekim 26-28.

Arslanoğlu İ. (2019). Şebekeden Bağımsız Sinüzoidal Darbe Genişlik ile Uzay Vektör Darbe Genişlik Modülasyonlarının Karşılaştırmalı Performans Analizi, Yüksek Lisans Tezi, Munzur Üniversitesi Fen Bilimleri Enstitüsü, Tunceli

Asker, M. E., Özdemir, M., Bayındır, M. I. (2009). Sinüzoidal DGM ile uzay vektör DGM yöntemlerinin karşılaştırılmalı incelenmesi. 5. Uluslararası ileri Teknolojiler Sempozyumu (IATS'09), Karabük, Türkiye.

Beşer, E. (2009). Anahtarlama elemanı sayısı ve harmonik optimizasyonu ile bir fazlı çok seviyeli evirici tasarımı, Yüksek Lisans Tezi, Kocaeli Üniversitesi Fen Bilimleri Enstitüsü, Kocaeli.

Canbaz, R. (2014). Üç seviyeli diyot kenetlemeli evirici ile çıkış geriliminin sabitlenmesi, Yüksek Lisans Tezi, Gazi Üniversitesi Fen Bilimleri Enstitüsü, Ankara.

Deniz, E. (2010). Uzay vektör darbe genişlik modülasyonu kullanan üç seviyeli H-köprü evirici tabanlı Dstatkom'un tasarımı ve gerçekleştirilmesi, Doktora Tezi, Frrat Üniversitesi Fen Bilimleri Enstitüsü, Elazığ.

Eskin, A. (2012). Alternatif enerji sistemlerinde kullanılan çok seviyeli eviricilerin İncelenmesi, Yüksek Lisans Tezi, Yıldız Teknik Üniversitesi Fen Bilimleri Enstitüsü, İstanbul.

Fidanboy, H. (2011). Farklı darbe genişlik modülasyon teknikleri ile sürekli mıknatıslı senkron motorun performans analizi, Yüksek Lisans Tezi, Gazi Üniversitesi Fen Bilimleri Enstitüsü, Ankara.
Kang D.W., Lee Y.H., Suh B.S., Choi C.H., Hyun D.S. (2000). An improved carrierwavebased SVPWM method using phase voltage redundancies for generalized cascaded multilevel inverter topology, Applied Power Electronics Conference and Exposition. APEC 2000. Fifteenth Annual IEEE, February, 542-548.

Kerem A. (2012). 6 Anahtarlı 3 seviyeli evirici tasarımı, Yüksek Lisans Tezi, Gazi Üniversitesi Fen Bilimleri Enstitüsü, Ankara

Kocalmış A. (2005). Uzay vektör PWM kontrollü çok seviyeli inverterin modellenmesi ve benzetimi, Yüksek Lisans Tezi, Fırat Üniversitesi Fen Bilimleri Enstitüsü, Elazığ.

Kocalmış Bilhan, A. (2012). Bölge ve sektör tespitinde yapay sinir ağları kullanan uzay vektör darbe genişlik modülasyon kontrollü kaskat bağlı üç seviyeli evirici tasarımı, Doktora Tezi, Furat Üniversitesi Fen Bilimleri Enstitüsü, Elazı ğ.

Kocatepe, C., Uzunoğlu, M. ve Yumurtac1, R. (2003). Elektrik Tesislerinde Harmonikler, Birsen Yayınevi, İstanbul.

Önder, H. İ. (2010). Basamaklı çok katlı eviricilerin asenkron motorlarda uygulanmasının analizi, Yüksek Lisans Tezi, Gazi Üniversitesi Fen Bilimleri Enstitüsü, Ankara.

Rathnakumar, D., Perumal, J.L., Srinivasan, T. (2005). A new software implementation of space vector PWM, IEEE Southeast Conference, India, 8-10 April, 131136.

Sünter, Z. (2013). Tek fazlı gerilim kaynaklı eviricilerde harmonik eiminasyonueliminasyonu için yeni bir yaklaşım, Yüksek Lisans Tezi, Fırat Üniversitesi Fen Bilimleri Enstitüsü, Elazığ.

Tuncer, S. (2004). Uzay vektör darbe genişlik modülasyonu kullanan beş seviyeli inverter tasarımı ve uygulamas1, Doktora Tezi, Firat Üniversitesi Elektrik Elektronik Mühendisliği, Elazı̆̆.

Yumurtacı, M. (2007). Çeşitli modülasyon tekniklerinin harmonik bozulma üzerindeki etkileri, Yüksek Lisans Tezi, Afyon Kocatepe 